\title{
Out-Patient Surgery
}

By George J. Hill

W. B. Saunders Company, Philadelphia, USA 1988. 729 pp. $£ 37.50$.

This reviewer is not an avid reader of text books so I have approached this one with a degree of scepticism. Since it is the 3rd edition within 15 years I presume somebody must be reading it. It is in effect a text book of surgery but looked at through the eyes of someone working in out-patients. This seems bizarre to someone working in the UK but on the continent and in North America from where the book originates it may have more relevance. Perhaps a better title in the UK would be 'Surgery that can be done as a Day Case or in the Accident and Emergency Room'. It covers surgery that can be done within $1 \mathrm{~h}$ and requires less than a 2-h stay in the recovery room. In the first chapter there are lists of suitable operations and the numbers performed per annum in the USA.

For a student wishing to learn surgery there are better text books than this. For a junior surgeon wishing to learn details of operative techniques there are also better places to find the information. Having said that, what is written in the book is perfectly clear and well illustrated. I can see it being of use on a shelf in an accident and emergency department, where one wanted to read up a little about a subject that was outside ones own area. It provides an interesting alternative approach to the study of a wide range of surgical subjects.

\section{E. S. KIFF}

Department of Surgery, Withington Hospital, Manchester, England

\section{Yearbook of Emergency Medicine 1989}

Edited by David K. WAGNeR

Yearbook Medical Publishers, Inc., Chicago, London \& Boca Raton, 1989. 300 pp.

This is the 10th Year Book of Emergency Medicine, and as the editor points out in his introduction the past decade is one in which the specialty has become accepted and developed its own unique body of knowledge. This year's volume reflects many of the changes that are occurring within the specialty in North America and to a lesser extent in Europe. As in previous editions much space is devoted to aspects of resuscitation. The selection of such articles is of high quality, the synopses are clear and the editorial comments invariably pertinent.

It is chastening to see the extent and quality of such research being performed in North America and by contrast the poor representation both from the United Kingdom and the rest of Western Europe. In relation to this the two principal accident and emergency journals in the United Kingdom are not even cited in the Journal scaneditors please note.

One of the joys of this type of book is that it can be used both as a way of rapidly 